\title{
Smartphone-based System for water quality analysis
}

\author{
Satyam Srivastava ${ }^{1} \cdot$ Saikrishna Vaddadi $^{1} \cdot$ Shashikant Sadistap $^{1}$
}

Received: 2 January 2018 / Accepted: 31 July 2018 / Published online: 6 August 2018

(c) The Author(s) 2018

\begin{abstract}
Water quality in rural areas is difficult to monitor due to lack of connectivity from different water laboratories. In other areas, location-based real-time water quality data collection is a tedious job and highly dependent on human intervention. The presented paper introduces a low-cost battery operated smartphone-based embedded system design to measure different water quality parameters in various remote locations. Developed system measures $\mathrm{pH}$, total dissolved salt (TDS) and temperature of the water samples using off the shelf available sensors. Measured $\mathrm{pH}$ and TDS dataset have been used to derive other water quality parameters using standard mathematical relationships such as salinity, oxygen reduction potential and conductivity. Front-end readout interface circuit has been designed and interfaced with 8-bit microcontroller along with classical Bluetooth module for measurement, data acquisition, and logging purpose. A dedicated smartphone-based application offers analysis and cloud data storage possibilities. It also provides facility to analyze water quality data with location information on Google map for quick judgment and easy understanding. The developed smartphone-based application provides the facility of auto-calibration feature for rapid and on-site usage. Developed smartphone-based application also opens up the possibility to share the data and warnings using different options such as SMS, WhatsApp and E-mail. Overall device has dimensions of $11.0 \times 8.0 \times 4.0$ (in cm), weighs $350 \mathrm{~g}$ and runs with $9-\mathrm{V}$ rechargeable battery. Obtained results have been validated with standard water quality measurement system from Eutech Instruments, and it has been observed that measured and calculated parameters are acceptable according to Indian water quality standards. Various statistical and artificial neural network-based modeling techniques have been used to convert measured water quality parameters to a single water quality index for easy and rapid judgment. The developed water quality measurement system has been used for multiple applications to explore the utility of the system such as instant water quality judgment and real-time water quality analysis of different water sources. One of the other explored applications is the real-time water quality monitoring of small ponds and lakes.
\end{abstract}

Keywords Water quality sensors $\cdot$ Portable embedded system $\cdot$ Water quality index

\section{Introduction}

Location-based remote water quality monitoring and data collection have been always a great challenge for different water laboratories and public health engineering departments (PHED). Most of the water laboratories and public health engineering departments are highly dependent on

Satyam Srivastava

satyamsrivastava@ceeri.res.in

Saikrishna Vaddadi

sai@ceeri.res.in

Shashikant Sadistap

shashikant_s@ceeri.res.in

1 Academy of Scientific and Innovative Research (AcSiR), CSIR-CEERI, Pilani, Jhunjhunu, Rajasthan 333031, India manual data collection and storage process, which is timeconsuming and highly prone toward human error. Recently, there is a grown interest in the area of remote water quality data collection using various approaches such as wireless sensing node-based water quality measurement Rasin and Abdullah (2009), GPRS-based remote water quality analysis Ionel et al. (2015) and many more. Real-time water quality monitoring is a key to understand the chemical, physical and biological parameters of water samples and also to take remedial action as and when the need arises. Water quality judgment depends on large numbers of parameters such as chemical, physical and biological parameters. Physiochemical parameters measurement and monitoring are the most concerned issues according to water quality status of various Indian states Singh et al. (2012). In early age, water quality measurement was totally dependent on 
various chemical methods which are time-consuming, less reliable and required skilled human intervention Bartram and Ballance (1996); CPCB, Guide Manual. Further, colorimetric-based water quality sensing kits Ellerbee et al. (2009); Daniel et al. (2009) are also introduced by several researchers and few of them also reached up to commercialization [APPLIED MEMBRANES INC., homepage; HANNA instruments, homepage]. Indian water laboratories and public health engineering departments (PHED) rely on chemical-based methods and stand-alone instruments for water quality evaluation and database generation. Various water quality assessment methods have been reported in different studies such as monitoring of: lakes or ponds Haider et al. (2016); Kafli et al. (2016); Wiranto et al. (2015); Siyang and Kerdcharoen (2016), swimming pool Marais et al. (2016), wastewaters Oscanoa et al. (2016) and potable waters GH (2015); Regan et al. (2009). Recently, there has been a growing interest to develop smart water quality sensor-based systems along with different advanced features such as wireless data communication, alarm indication and auto-calibration Putra and Harsono (2016); Lee and Deininger (1992); Cloete et al. (2016). Few efforts have been observed in the direction to develop a floating water quality monitoring systems to assess the water quality of ponds and lakes. Most of them are manually driven Ethier and Bedard (2007); Vaddadi et al. (2012); Kafli et al. 2016, while some are autonomous Dunbabin et al. (2009). Power usage is one of the crucial aspects in such kind of applications, and continuous efforts have been observed in the direction of low power technology development. Researchers tried to solve power usage problem by connecting water quality measurement system with a solar panel Konyha (2016). Water quality indexing is also one of the key challenges and needs to be addressed, especially in case of drinking water. Multiple sensing variables such as $\mathrm{pH}$, TDS, ORP, salinity, conductivity and many more need to be processed using different modeling techniques and convert them into a single water quality index. A single parameter-based water quality index can be easily evaluated. Few efforts have been observed in the direction of converting multiple water quality parameters into a single water quality index using rule-based fuzzy model Roveda et al. (2010) and neural network Gorashi and Abdullah (2012). Non-contact-based sensing techniques also have been explored for water quality parameters measurement. Simple led and photodiode-based optical sensing setup for turbidity measurement Komiyama et al. (2015) and ultrasonic-based water quality measurement Khairi et al. (2015) have been discussed by several researchers, but most of them have not reached up to maturity level. Finally, water quality evaluation still implies various challenges such as low power readout interface design, automatic data transfer, storage, portability, water quality indexing, analytics and many more. Presented work introduces a handheld smartphone-based device to analyze the water quality along with location information of testing sites in different applications. This device requires low power and uses smartphone for data storage and analysis. Dedicated Android application stores water quality parameters on the smartphone, transfers to the cloud with location information, predicts water quality index in real-time and also provides facility to integrate water quality data with Google map for rapid judgment and analysis at district, state and country level. The rest of the manuscript is organized as follows. Section II provided a detailed description of the embedded system for water quality inspection. Section III consists of the description of the implementation procedure for the smartphone-based Android application, along with its feature and utility. Section IV discusses the algorithms used for water quality indexing. Section V presents testing of the proposed system for different water quality evaluation scenarios. Section VI includes the performance evaluation, while the conclusions have been shown in section VII.

\section{Embedded system design and development}

An embedded processing unit has been designed and developed to acquire the data from off the shelf available sensors imported from Toshcon Corporation \& Ltd. Measured $\mathrm{pH}$ and TDS dataset have been used to predict other water quality parameters such as salinity, conductivity and ORP using standard mathematical models. Measured and derived water quality parameters have been used to predict a water quality index by means of different statistical modeling techniques. Developed smartphone-based handheld embedded system for water quality measurement is a step toward the development of a lightweight, low cost and easy to use modular embedded water quality inspection system.

\section{Hardware development}

The embedded system (Fig. 1) consists of various submodules such as signal conditioning unit, microcontroller unit, classical Bluetooth module and a rechargeable battery. The signal conditioning unit represents resistance to frequency converter. It is used to measure the resistance variation of the TS sensor along with an analog front-end circuit (LMP91200) [Sensor AFE System] for $\mathrm{pH}$ sensor. Two different resistance to frequency conversion approaches have been explored and compared based on their performance. Filter-based noise removal and impedance matching conditioning have been integrated with the resistance to frequency conversion unit. Amplification scaling procedures are used to adjust the sensor response from 0 to $5 \mathrm{~V}$. Overall readout circuit has been interfaced with 8-bit microcontroller unit for data acquisition and processing. A classical Bluetooth module (HC-05) imported from element 


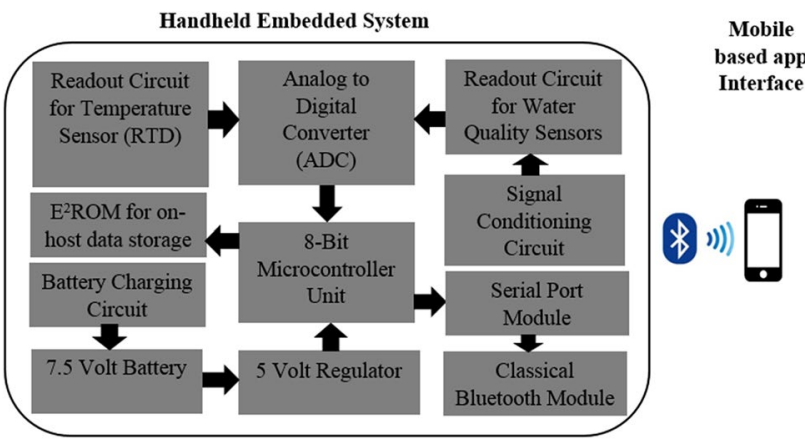

Fig. 1 Functional block diagram of proposed water quality measurement system

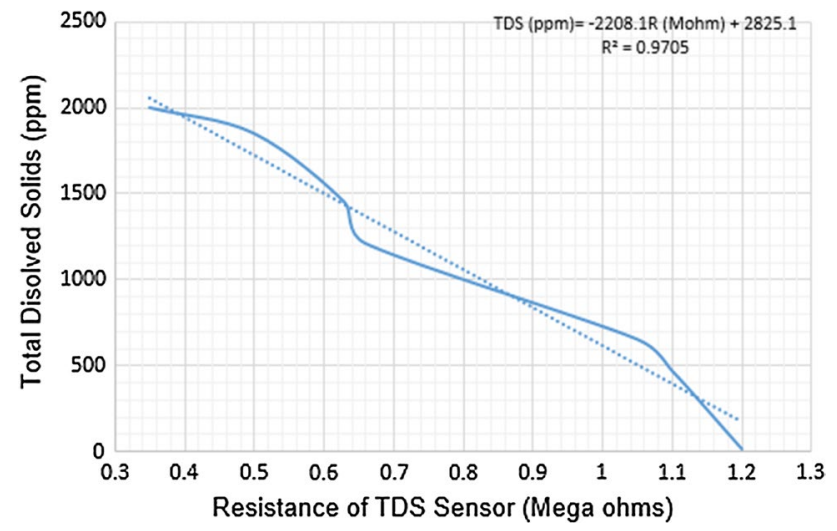

Fig. 2 TDS sensor characteristics $(\operatorname{TDS}=f(R))\left(\right.$ Temperature $\left.=20^{\circ} \mathrm{C}\right)$

14 Corp. Pvt. Ltd along with $E^{2}$ PROM has been integrated with microcontroller unit for on host data storage and data transfer to the smartphone. Overall, the embedded system is portable, low cost and easy to operate via smartphone-based android application. The system works on $7.5 \mathrm{~V}$ battery for more than $8-10 \mathrm{~h}$ continuously without charging.

The TDS sensor resistance varies (Fig. 2) from 1.5 to $0.350 \mathrm{M} \Omega$ for 0 to $2000 \mathrm{ppm}$ water sample.

First resistance to frequency conversion approach (Fig. 3) Bandyopadhyay et al. (2016) consists of a 555 timer-based astable multi-vibrator to convert sensor resistance information to frequency variation (Fig. 4).

$$
\begin{aligned}
& f=\frac{1.44}{\left(R_{y}+2 R_{x}\right) C} \\
& R_{x}=\frac{0.72}{f C}-R_{y}
\end{aligned}
$$

$\operatorname{TDS}(\mathrm{ppm})=-2208.1 R_{x}+2825.1$

$$
R_{x}=\frac{(2825.1-\mathrm{TDS}(\mathrm{ppm}))}{2208.1}
$$

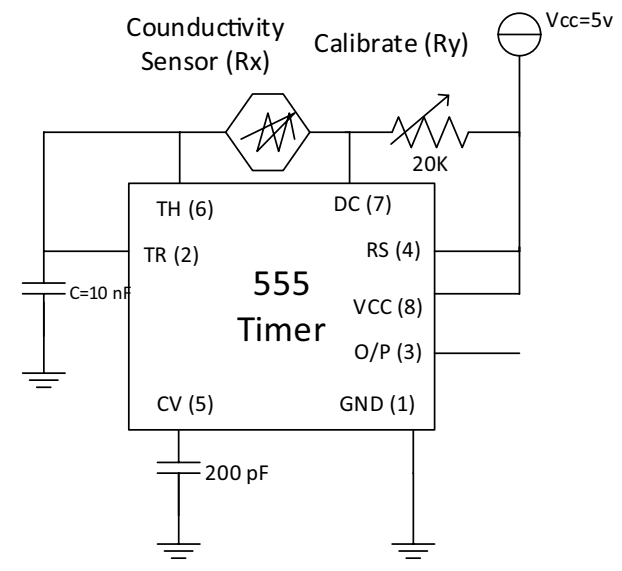

Fig. 3 Resistance to frequency conversion scheme (first TDS sensor readout approach)

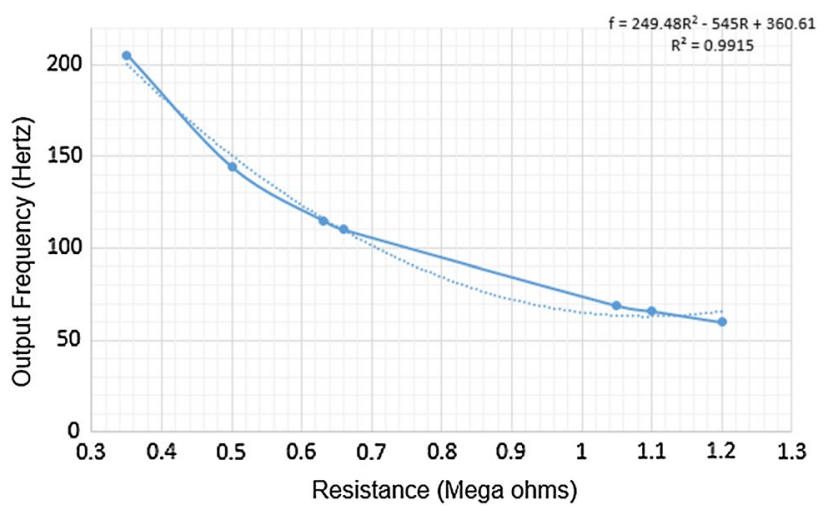

Fig. 4 Frequency characteristics using first approach $\left(F(\mathrm{~Hz})=f(R(\mathrm{M} \Omega))\left(\right.\right.$ Temperature $\left.=20^{\circ} \mathrm{C}\right)$

$f=\frac{1.44}{\left(R_{y}+(2825.1-\mathrm{TDS}) / 1104.05\right) C}$

where $R_{x}$ is the resistance of TDS sensor, and $R_{y}$ and $C$ are the values of the corresponding circuit elements. $R_{y}$ has been used for calibration.

One of the other resistance to time conversation approaches (Fig. 5) De Marcellis(2008) also has been explored to convert the resistance variation to time information. This approach works based on the integration of current flowing through the sensor exited by a D.C. pulse signal provided through closed-loop feedback. This scheme consists of three different stages such as integrator along with amplifier in primary stage to integrate the current flowing through the sensor, comparator unit in the second stage for threshold detection and ex-or gate in the last stage to eliminate the common feature in both signals. The timing of output signal depends on the current flowing through the sensor. Second resistance to frequency approach results has 


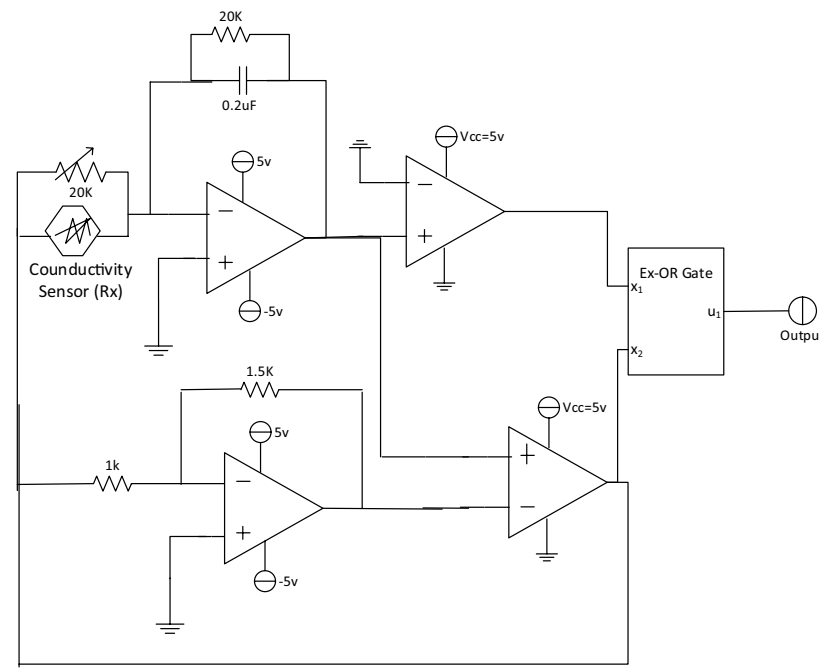

Fig. 5 Resistance to time conversion scheme for TDS sensor readout (second TDS sensor readout approach)

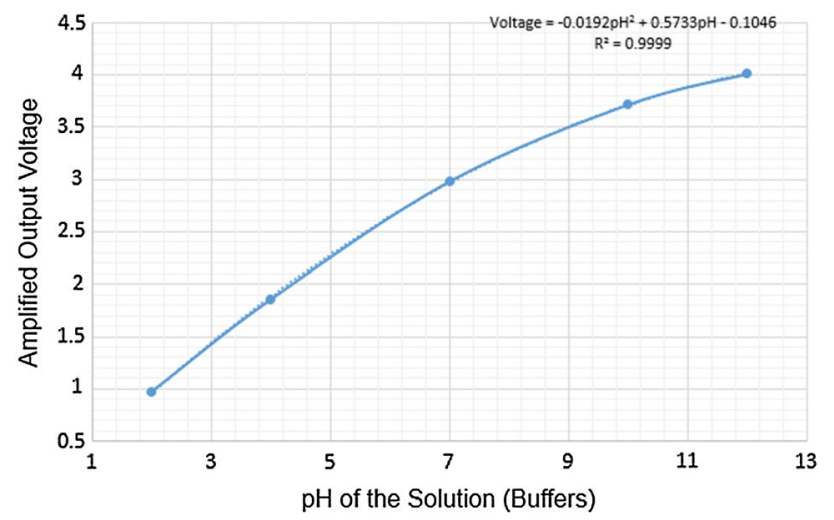

Fig. $6 \mathrm{pH}$ versus scaled output voltage curve recorded using $\mathrm{pH}$ sensor readout circuit $\left(\right.$ Temperature $\left.=20{ }^{\circ} \mathrm{C}\right)\left(R^{2}=0.99\right)$

been compared with the first one in the context of power consumption, portability and range. It has been concluded that, for our application, the first approach requires very less power, covers the target concentration range and occupies less physical space.

Commercially available low power analog front-end (LMP91200) [Sensor AFE System] imported from Texas Instruments has been used for $\mathrm{pH}$ sensor interface followed by impedance matching and amplification circuit. The output of the analog front-end (LMP91200) has been fed into the noise removal unit, amplification unit along with postscaling unit to scale signal from 0 to $5 \mathrm{~V}$ for 0 to $14 \mathrm{pH}$ buffer solutions (Fig. 6).

$\mathrm{K}$ type thermocouple has been used for temperature measurement of the water samples, and further data have been used to compensate the effect of temperature variation over $\mathrm{pH}$ and TDS sensor. Other parameters such as salinity,
ORP and conductivity have been derived from $\mathrm{pH}$ and TDS data using standard mathematical relationships. Embedded system schematic and functionality flow diagram have been presented as follows (Fig. 7).

\section{Software package development}

Various modular programs are written in cross $\mathrm{C}$ and $\mathrm{C}++$ compiler for the functioning of ATMEGA 328-based handheld water quality measurement system. The main software module initializes the water quality sensors, analog to digital converter, E2PROM, Bluetooth module, serial port and also checks all sensors connections along with battery level. A menu-driven program has been developed to operate smartphone-based water quality measurement system. Menu-driven program consists of testing and calibration submodules for testing of water samples and calibration of sensors, respectively. Calibration mode provides facility to calibrate device with standard buffer samples using 2, 3 and 5 point calibration algorithm.

The smartphone-based application provides facility to select the sensor type and calibration method and further uploads the calculated calibration coefficients (offset and gain value) of linear models to the device. Device saves calibration coefficients in $\mathrm{E}^{2} \mathrm{PROM}$ as a backup and also updates its prediction models with new calibration coefficients.

Measurement mode consists of various submodules for data acquisition, storage, water quality parameters prediction and data transfer to the smartphone. Predicted parameters converted in to a single data chunk along with start, stop and a parity bit for transferring data to the smartphone without any error. It also includes $\mathrm{I}^{2} \mathrm{C}$-based $\mathrm{E}^{2} \mathrm{PROM}$ read and write module to recall the stored calibration coefficients. All modular programs have been linked to the main menu program to operate smartphone-based water quality measurement system.

\section{Android-based smartphone app interface development}

A smartphone-based android application (Fig. 8) has been developed to communicate with the device using Bluetooth protocol. A classical Bluetooth module (HC-05) has been used to establish communication between handheld device and smartphone. The android application provides a frontend view to display water quality parameters along with temperature and battery level. It also provides facility to collect location information of water sites and store them on the smartphone in excel file format. Android app provides facility to connect the smartphone with Google firebase cloud and save per minute water quality data along with location information. As global positioning system coordinates 


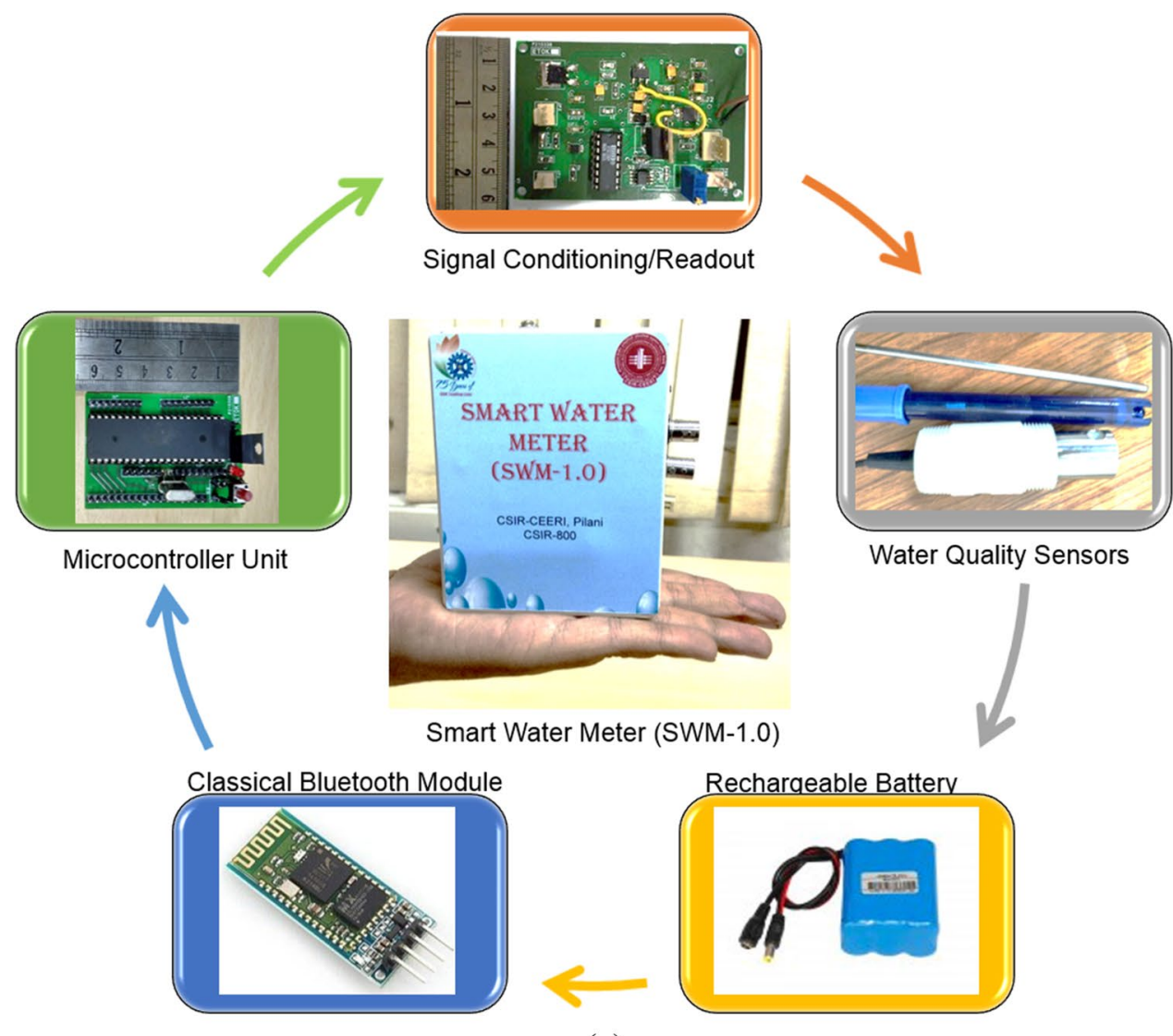

(a)

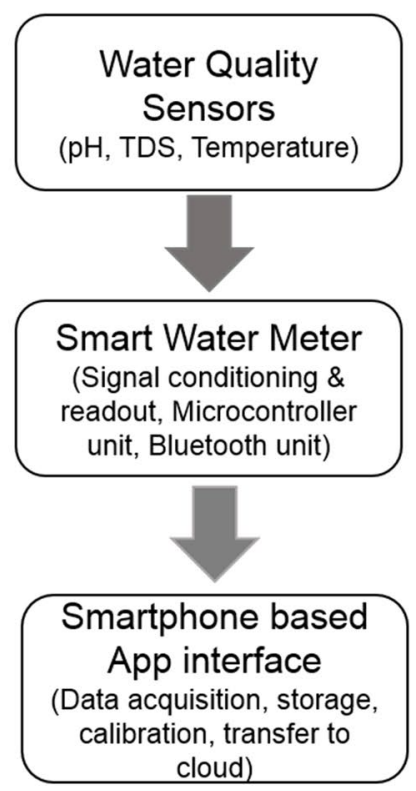

Fig. 7 a Schematic of various components of smart water meter prototype and $\mathbf{b}$ integration scheme of smart water meter (SWM-1.0)

changes only after moving a certain distance, but there could be a possibility that two water sites are so near that even global positioning system cannot discriminate them. Android application tackles the above-mentioned problem by providing facility to share testing site details, description and picture along with water quality information. Android application provides an on-site auto-calibration feature to calibrate sensors using different calibration methods such as 2, 3 and 5 point calibration and saves calibration history in the smartphone itself for record purpose. Android application provides multiple options to share location-based water quality data and warnings using multiple options such as SMS, WhatsApp and e-mail.

\section{Performance evaluation and applications}

Smartphone-based water quality measurement system has been tested with standard water quality measurement system PCD 650 imported from Eutech Instruments. Water samples collected from nearby villages and institute colony have been accessed using smartphone-based water quality measurement system. The similar set of samples have been accessed with standard water quality measurement system imported from Eutech instruments.

It has been observed that smartphone-based water quality measurement has an excellent accuracy (Fig. 9) to predict water quality parameters. The developed system shows excellent results to predict $\mathrm{pH}$, TDS, conductivity, salinity and ORP with the accuracy acceptable to Indian water quality standards. Presented work has been compared with past literature (Table 2), and it has been found that smartphone-based water quality measurement system could be a low-cost tool for location-based water quality measurement as well as it could be used in each Indian water quality measurement laboratory.

System has been tested for different water quality measurement applications such as handy water quality meter for instant water quality judgment, integrated with reverse osmosis plant for real-time water quality monitoring and also converted into a floating water quality monitoring node to assess the water quality of small lakes and ponds. 


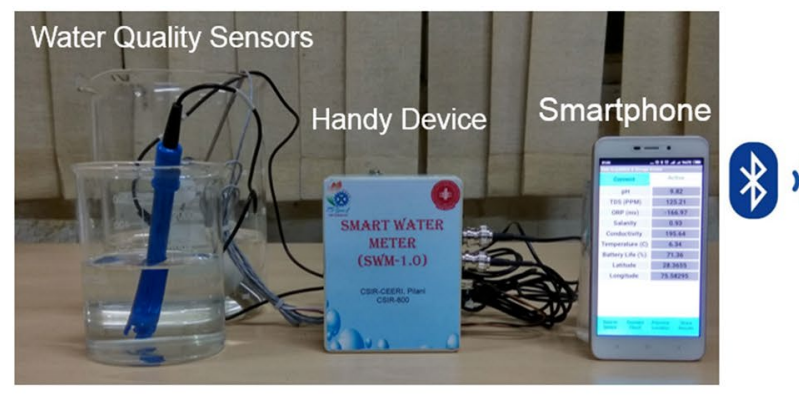

Smartphone based water quality measurement system

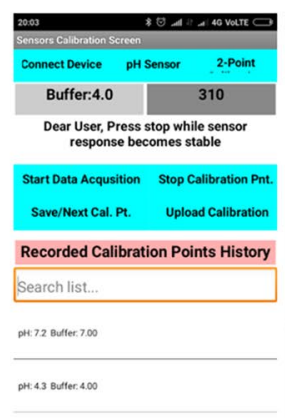

Sensors calibration screen

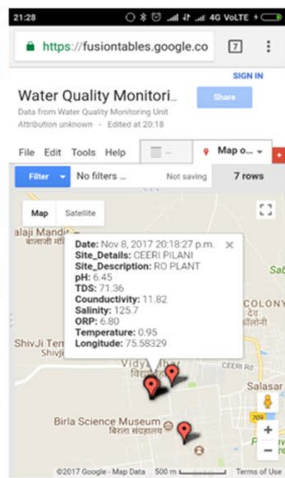

Google Map View

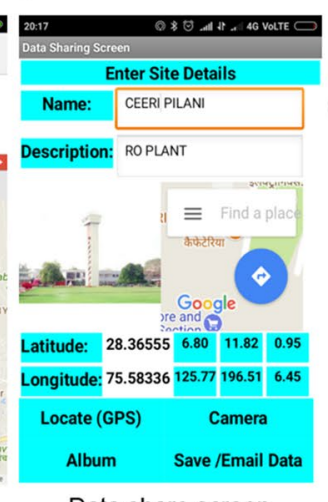

Data share screen

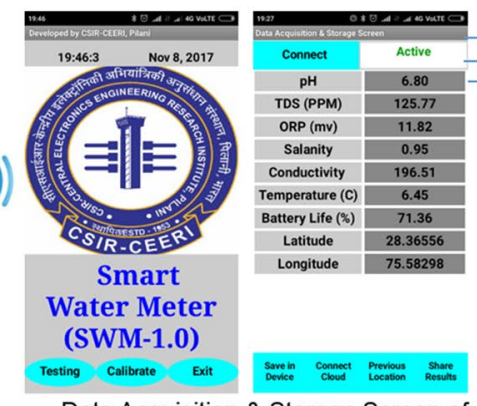

Data Acquisition \& Storage Screen of Android App

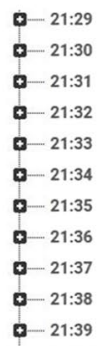
$-19: 27$

D-Nov 4, 2017

D-Nov 7, 2017

D- Nov 8, 2017

D- Oct 11, 2017

- Oct 25, 2017

D- Oct 26, 2017

- Oct 29, 2017

- Oct 3, 2017

- Oct 30, 2017

Oct 8,2017

- $21: 3$

Data stored in Cloud (date \& minute wise)

Fig. 8 Smartphone-based water quality measurement system operation with different features of developed android app

\section{A real-time water quality monitoring}

System has been integrated with reverse osmosis water purification plant installed in institute campus for input and product water quality monitoring (Fig. 10). A cylindrical shape sampling chamber made of plastic along with three D.C. solenoid valves has been used to maintain the constant water flow. Sensors have been installed inside the sampling chamber for water quality measurement. Valves have been controlled by reverse osmosis controller unit. Product and raw water have been passed alternatively through the sampling chamber. Installed water quality measurement system transfers water quality information to the smartphone-based android application and also to cloud for record and analysis purpose.

\section{Floating water quality monitoring system}

System has been integrated with a plastic cubic hollow platform having dimensions of $12 \mathrm{~cm} \times 10.0 \mathrm{~cm} \times 6.0 \mathrm{~cm}$ to monitor the water quality of small ponds and lakes (Fig. 11). The direction of the floating system has been managed by a string tied to the platform as well as wind flow. System acquires water quality data per minute. System has been tested in institute small fountain pond, and acquired data have been transferred to the cloud using smartphone app interface. Overall idea is to demonstrate the utility of smartphone-based water quality monitoring system for water quality monitoring of small ponds and lakes. Floating system has been tested for ten days. Average readings of each day for every water quality parameter have been calculated and presented as follows (Fig. 11).

\section{Instant water quality judgement}

System also has a potential to use for instant water quality judgment at different rural and urban places. System has been tested at different villages, and location-based water quality data (Fig. 12) have been transferred to the cloud. Collected location-based water quality data have been integrated with Google map for analysis at the village level. Acquired water quality data have been used to predict water quality index using different statistical and ANN-based techniques. Water quality can be easily and instantly judged based on the predicted water quality index with different thresholds. Smartphone-based app also shows warning in the form of color indication based on the quality of the tested water sample. Red color indicates for totally contaminated and non-drinkable, yellow for mordantly contaminated and needs treatment before drinking and green for safe drinkable water. System has been tested at seven nearby villages of Rajasthan. The overall idea is to demonstrate the concept of automatic water quality 


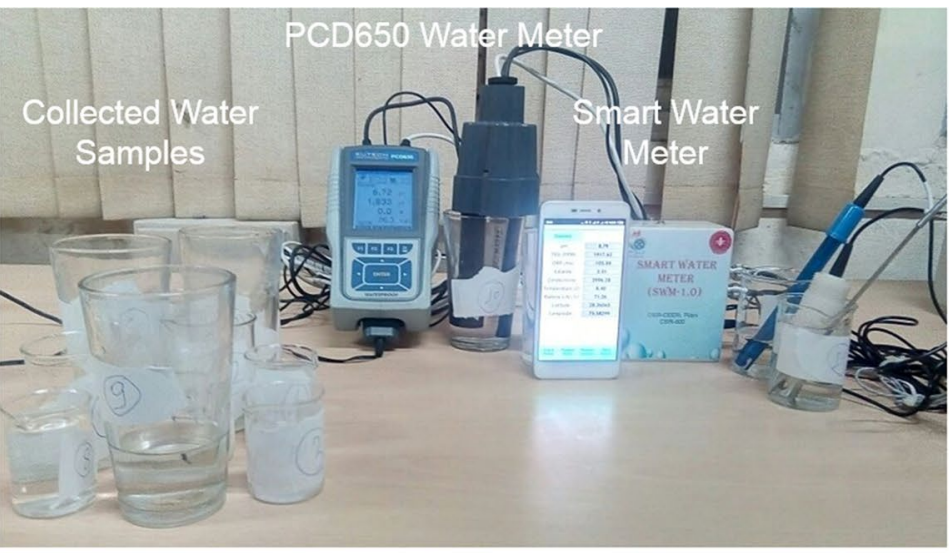

(a)

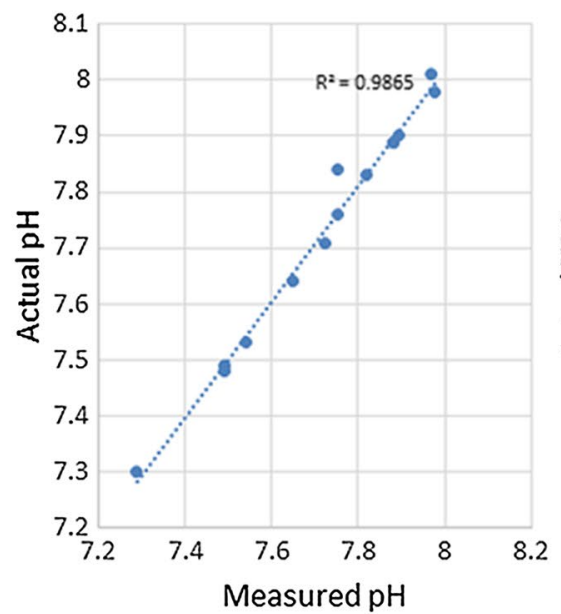

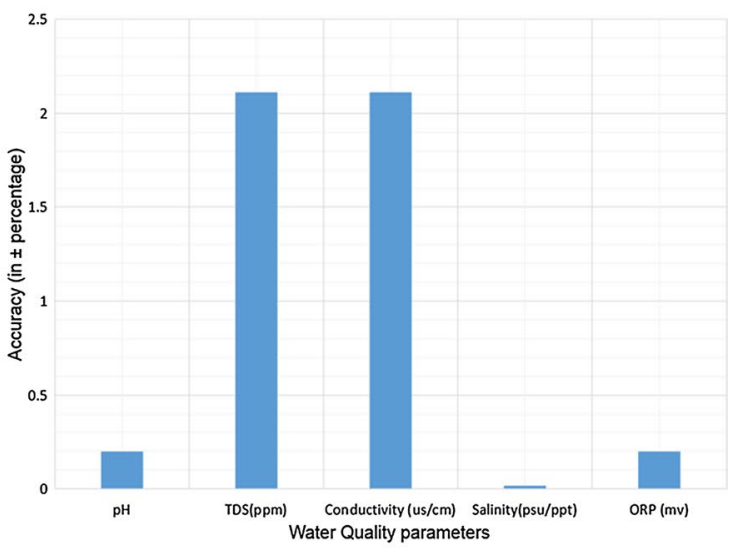

(b)

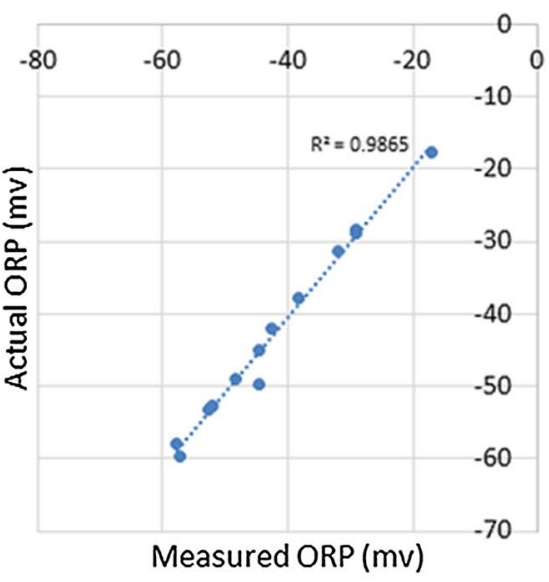

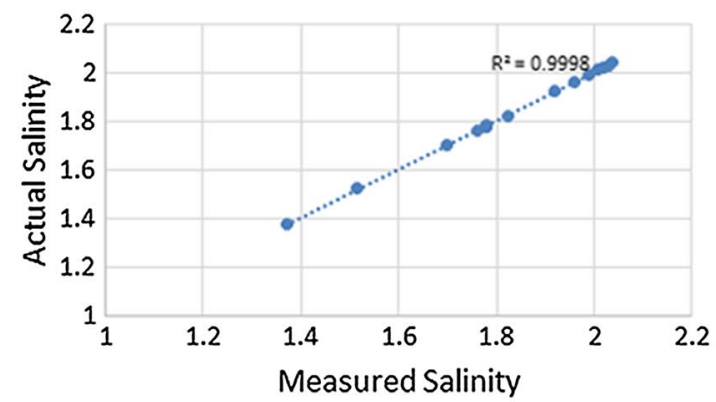

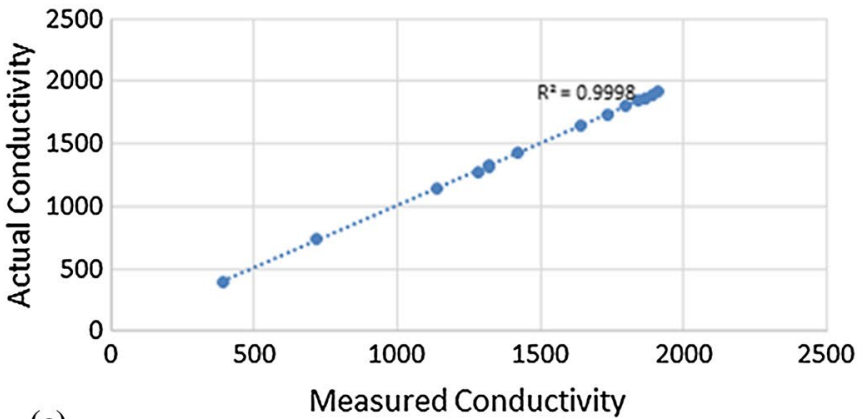

(c)

Fig. 9 a Experimental setup for developed system validation, $\mathbf{b}$ accuracy plot of various water quality parameters and $\mathbf{c}$ measured water quality parameters vs actual water quality parameters

data collection along with location information. The presented method is less prone toward human error and highly useful for Indian water laboratories and public health engineering departments for water quality data collection of different rural and urban locations.

\section{Water quality indexing}

Water quality depends on several physiochemical parameters and complex to understand for a common person. It is difficult to judge the water quality based on the variation of multiple water quality parameters. Water quality 

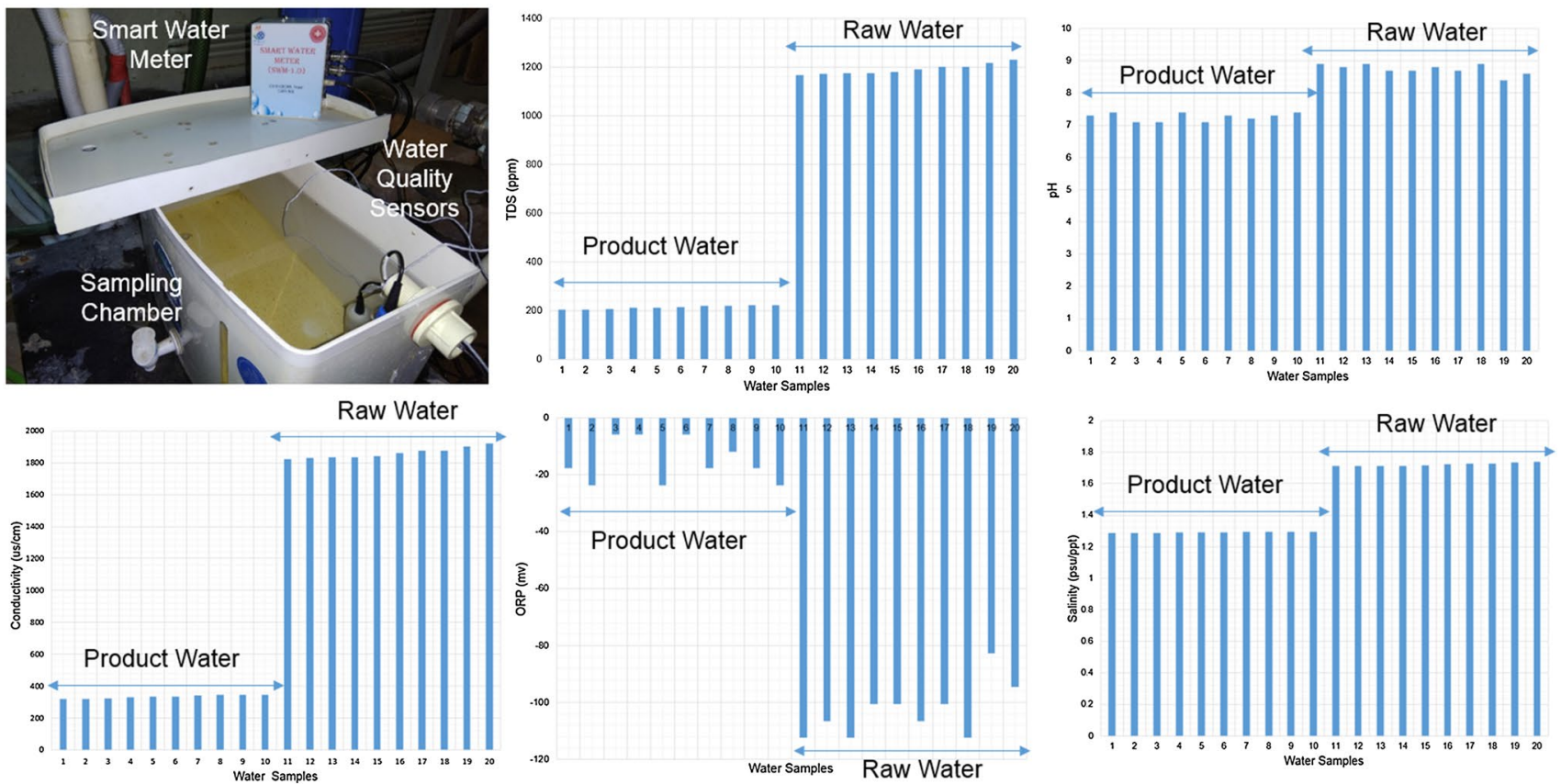

Fig. 10 Integration of smart water meter with RO plant for real-time water quality monitoring
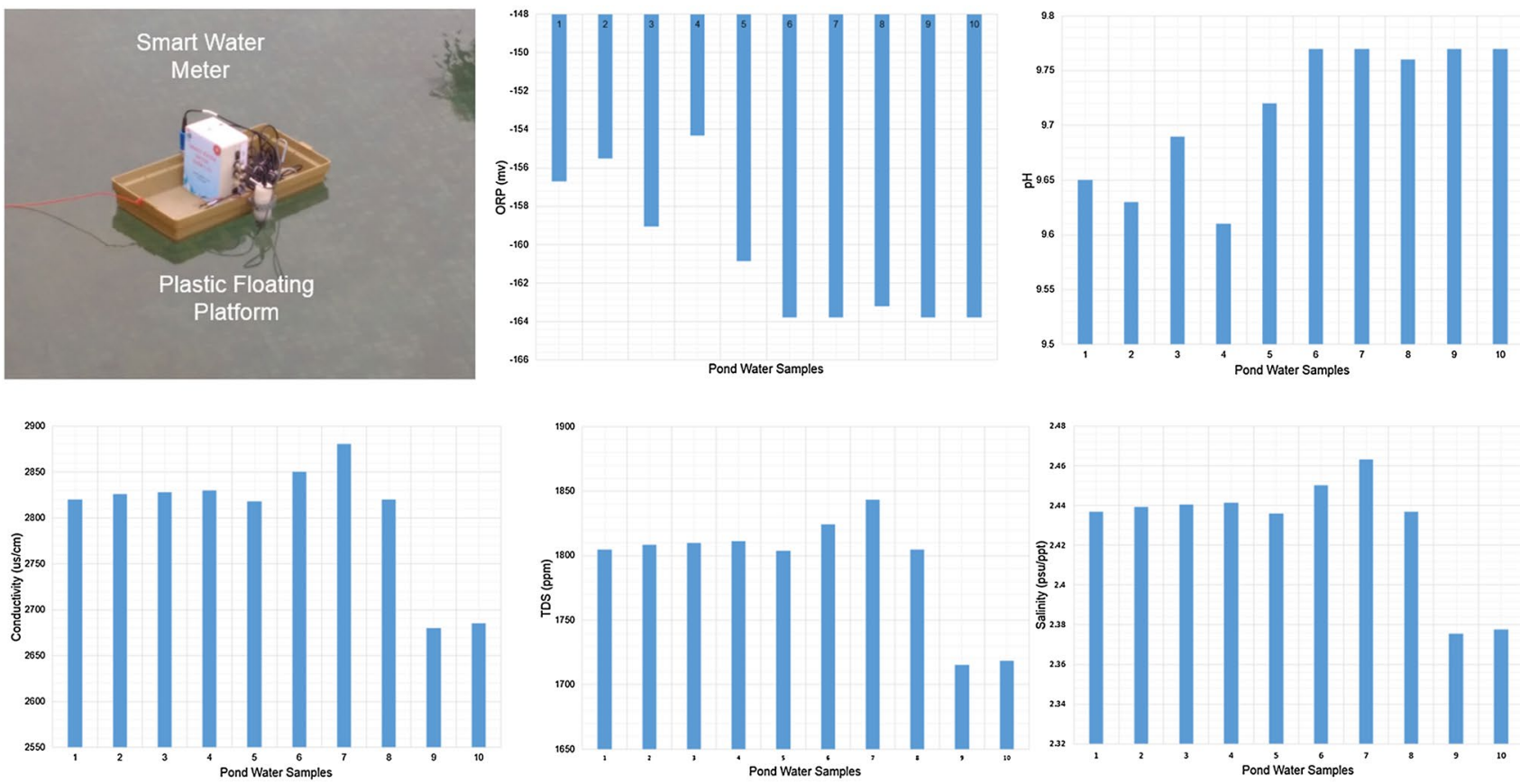

Fig. 11 Floating water quality monitoring system along with acquired water quality parameters of pond water

index (WQI) is an important and unique rating to depict the overall quality of water in a single term, and also it is easy to understand for everyone to select the right quality of water or to select appropriate treatment technique to improve the quality of water Tyagi et al. (2013). Water quality measurements are often processed using various mathematical models to find the score for water quality status. Several models for water quality indexing have been explored using different methods such as weighted average method, weighted geometric mean method, minimum 

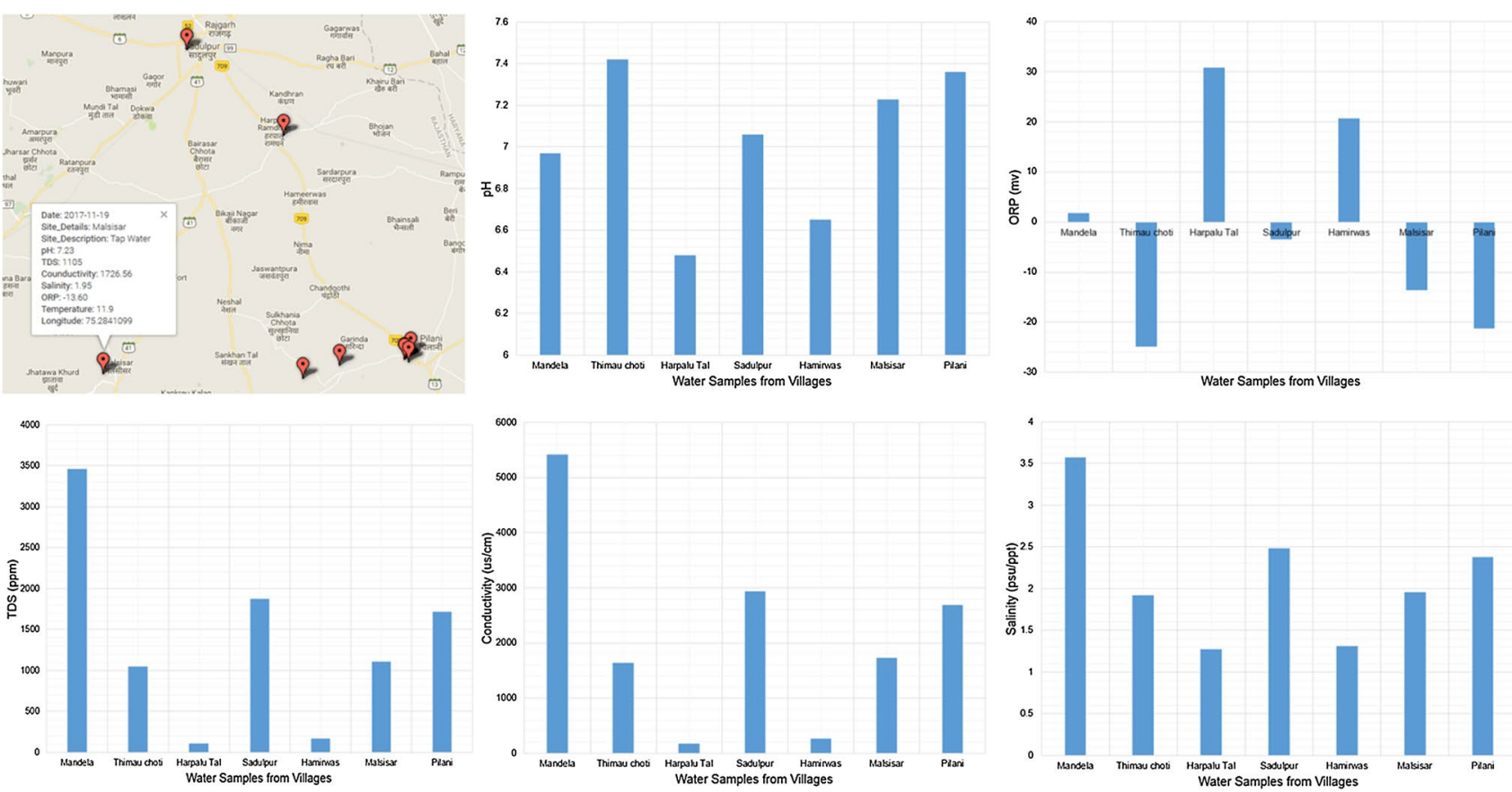

Fig. 12 Collected location-based water quality data of nearby villages of Rajasthan
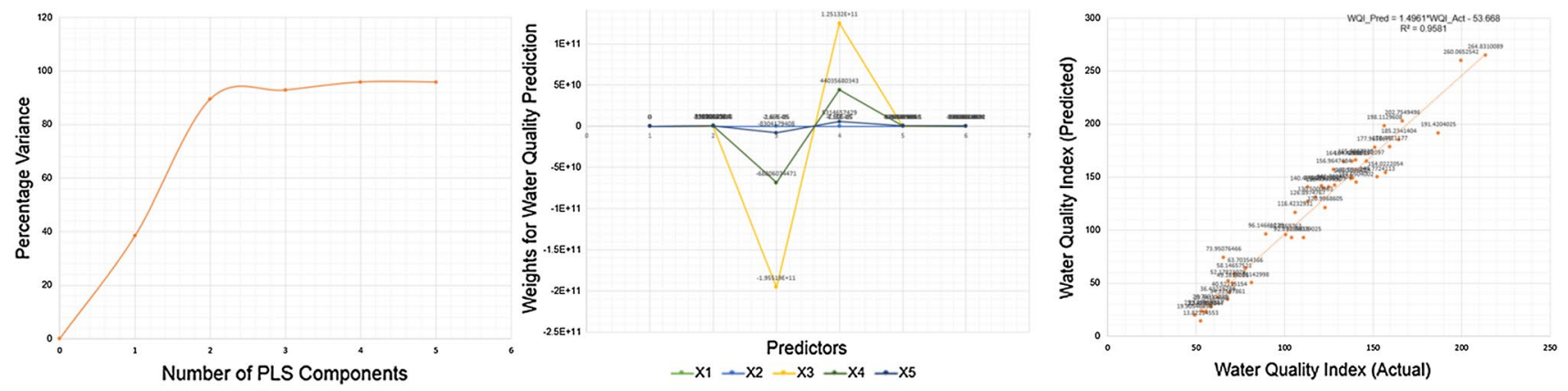

Fig. 13 Water quality indexing prediction using partial least mean square regression (PLSR)

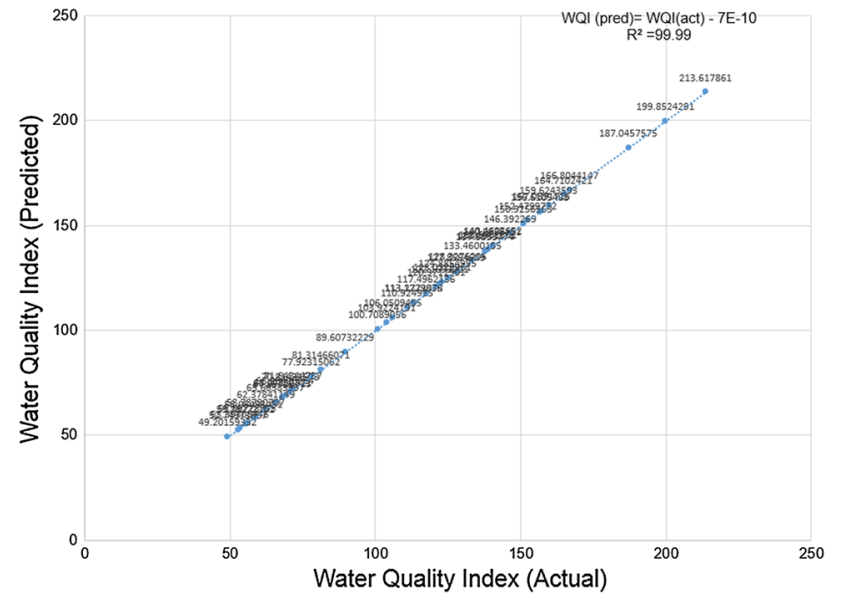

Fig. 14 Predicted water quality index using multiple linear regression (MLR) method operator and hybrid methods. Most of these methods process different water quality parameters using basic mathematical operations with standard weights and calculated sub-index Krishan et al. (2016).

Few of the algorithmic approaches such as partial least mean square regression based Sim et al. (2015) and fuzzy based Bai et al. (2009) have been tried to make water quality prediction process more intelligent and less time-consuming. As it is difficult to correlate single water quality parameter with water quality index, researchers have used several water quality parameters to predict water quality index such as $\mathrm{pH}$, TDS, TSS, DO, BOD, COD and many more. Selection of water quality parameters to predict water quality index is a very important step and should be selected on the location and application basis. Selection of a large number of input parameters makes WQI prediction model complex 
Table 1 Performance comparison of three different training techniques used of water quality index prediction

\begin{tabular}{llll}
\hline Training algorithm & $\begin{array}{l}\text { Number } \\
\text { of neu- } \\
\text { rons }\end{array}$ & Testing $R^{2}$ & MSE (testing) \\
\hline Bayesian regulation & 2 & 99.98 & $0.03 \times 10^{-5}$ \\
Bayesian regulation & 4 & 99.99 & $0.005 \times 10^{-5}$ \\
Bayesian regulation & 6 & 99.99 & $6.138 \times 10^{-5}$ \\
Bayesian regulation & 8 & 99.99 & $0.005 \times 10^{-5}$ \\
Scaled conjugate gradient & 2 & 86.35 & 749 \\
Scaled conjugate gradient & 4 & 94.44 & 673.4 \\
Scaled conjugate gradient & 6 & 96.9 & 99 \\
Scaled conjugate gradient & 8 & 99.98 & 0.543 \\
Levenberg-Marquardt & 2 & 99.98 & $3166.3 \times 10^{-5}$ \\
Levenberg-Marquardt & 4 & 99.99 & $2.1826 \times 10^{-5}$ \\
Levenberg-Marquardt & 6 & 99.99 & $0.663 \times 10^{-5}$ \\
Levenberg-Marquardt & 8 & 99.99 & $0.0001212 \times 10^{-5}$ \\
\hline
\end{tabular}

and time-consuming. Five different water quality parameters such as $\mathrm{pH}$, TDS, salinity, conductivity and ORP have been selected according to Rajasthan water quality scenario and further used for water quality indexing. Target water quality index values have been calculated using weighted arithmetic index method Sengupta and Dalwani (2007) for collected water quality samples data from various villages of Rajasthan. Standard and ideal values have been taken from Bureau of Indian Standards (BIS) for drinking water. Various statistical methods have been implemented to predict water quality index and further compared based on their accuracy and complexity.
Further, artificial neural network-based learning scheme with three different training techniques also have been explored to predict water quality index and results have been compared with results obtained with statistical modeling methods.

\section{Statistical modeling}

Various statistical methods have been implemented to predict water quality index, and results have been compared based on their prediction accuracy. Principle component regression (PCR) Jolliffe (1982), partial least square regression (PLSR) Sim et al. (2015) and multiple linear regression (MLR) Grégoire (2014) have been implemented on acquired water quality parameters data to predict water quality index. Selection of latent input variables to generate reliable prediction models is a crucial step. As less number of input latent variables can loss the information, while a large number of input variables can lead toward complexity. Variance analysis (Fig. 13) has been performed to select the optimal number of PLS components. Overall five input latent variables have been selected for the water quality index prediction model based on the variance analysis.

MLR, PCR and PLSR statistical modeling techniques have been used for water quality index prediction model, and it has been observed that PLSR method predicts water quality index less accurate (Fig. 13) $\left(R^{2}=95.81 \%\right)$ compared to other two methods. PCR and MLR predict better results $\left(R^{2}=99.99 \%\right)$ (Fig. 14) compared to PLSR.

The reason behind the higher accuracy could be the method used for target water quality index prediction. As
Fig. 15 Water quality indexing of nearby villages of Rajasthan

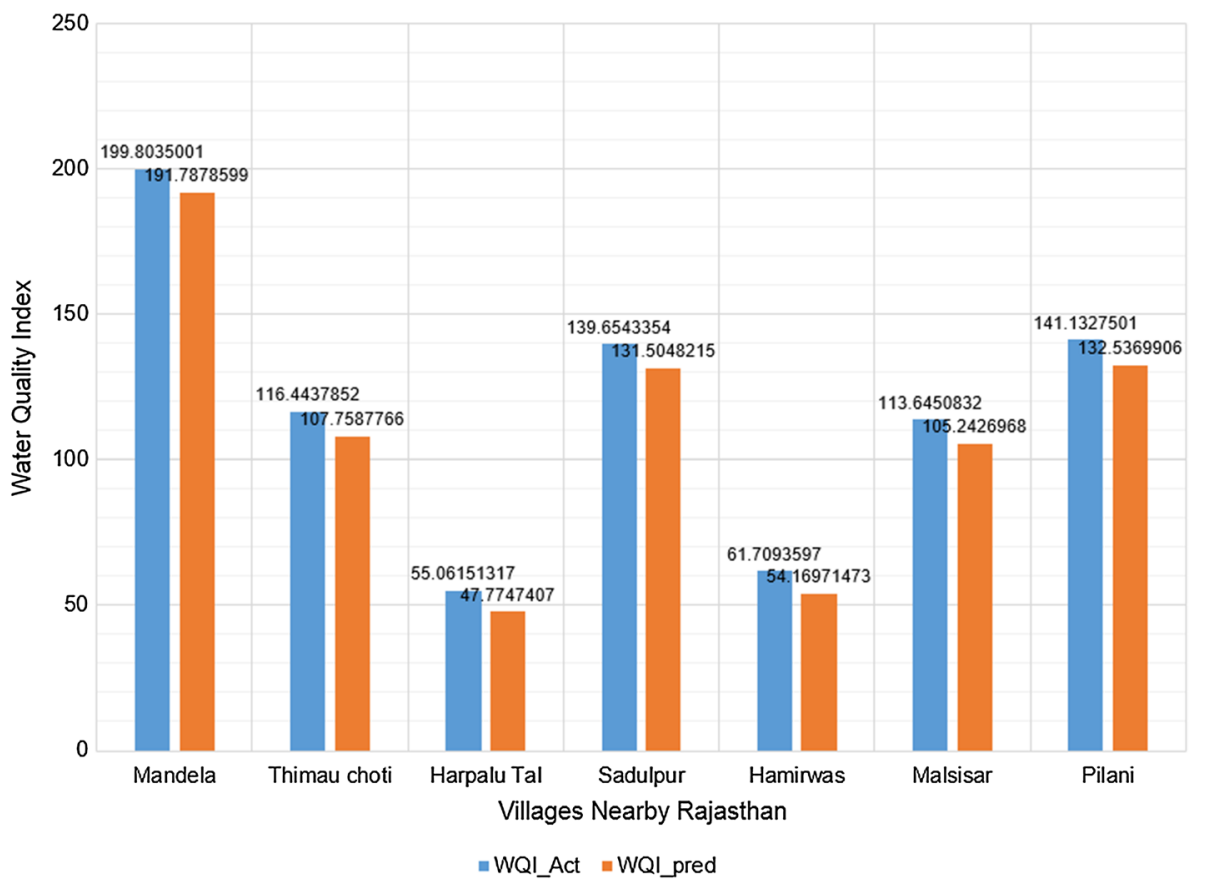


Table 2 Comparison of presented work with previous literature

\begin{tabular}{|c|c|c|c|c|}
\hline $\mathrm{SN}$ & Measurement technique details & Instrumentation details & Predicted parameters & References \\
\hline 1 & $\begin{array}{l}\text { Colorimetric-based sensing } \\
\text { techniques }\end{array}$ & $\begin{array}{l}\text { Smartphone with opto-mechan- } \\
\text { ical arrangement for color } \\
\text { detection }\end{array}$ & Mercury content in water samples & Wei et al. (2014) \\
\hline 2 & $\begin{array}{l}\text { Fluorescence-based sensing tech- } \\
\text { nique (chemical based) }\end{array}$ & $\begin{array}{l}\text { Smartphone with opto-mechan- } \\
\text { ical arrangement for color } \\
\text { detection }\end{array}$ & $\mathrm{pH}$ & Hossain et al. (2015) \\
\hline 3 & $\begin{array}{l}\text { Colorimetric-based sensing tech- } \\
\text { niques (chemical based) }\end{array}$ & $\begin{array}{l}\text { Smartphone with opto-mechan- } \\
\text { ical arrangement for color } \\
\text { detection }\end{array}$ & Chlorine & Sumriddetchkajorn et al. (2013) \\
\hline 4 & Contact type sensing technique & $\begin{array}{l}\text { Portable embedded system for } \\
\text { data acquisition and transfer to } \\
\text { PC using Xbee module }\end{array}$ & $\begin{array}{l}\mathrm{pH}, \text { conductivity, flow and tem- } \\
\text { perature }\end{array}$ & Cloete et al. (2016) \\
\hline 5 & Contact type sensing technique & $\begin{array}{l}\text { Laboratory level experimental } \\
\text { setup for measurement, data } \\
\text { acquisition, and storage, port- } \\
\text { able probe have been proposed } \\
\text { for future work }\end{array}$ & $\mathrm{pH}$, TDS and temperature & Haider et al. (2016) \\
\hline 6 & Non-contact sensing technique & $\begin{array}{l}\text { Lab level experimental setup for } \\
\text { measurement, data acquisition } \\
\text { and storage, }\end{array}$ & Turbidity & Murphy et al. (2015) \\
\hline 7 & Non-contact sensing technique & $\begin{array}{l}\text { Laboratory level experimental } \\
\text { setup for measurement, data } \\
\text { acquisition and storage }\end{array}$ & Turbidity & Komiyama et al. (2015) \\
\hline 8 & $\begin{array}{l}\text { Contact type measurement sens- } \\
\text { ing techniques }\end{array}$ & $\begin{array}{l}\text { Handy battery operated system } \\
\text { with smartphone-based app } \\
\text { interface for front-end, data } \\
\text { transfer to cloud, water quality } \\
\text { index prediction, on-site sensor } \\
\text { calibration }\end{array}$ & $\begin{array}{l}\mathrm{pH} \text {, TDS, salinity, conductivity, } \\
\text { ORP, temperature and Water } \\
\text { quality index }\end{array}$ & Present work \\
\hline
\end{tabular}

weighted arithmetic index uses the linear combination of water quality parameters and further calculates water quality index.

\section{Artificial neural network (ANN)-based modeling}

ANN-based modeling technique also has been explored to predict water quality index. Multi-input and single outputbased neural network architecture has been used to predict water quality index. Five water quality parameters have been used as inputs in the input layer and single output water quality index in the output layer. The optimal number of neurons in the hidden layer has been achieved using trial and error method (4 trials (neuron count $=2,4,6$ and 8) for each training algorithm). Three different training techniques such as Levenberg Marquardt, Bayesian regulation and conjugate gradient have been explored and implemented in MATLAB 2015a to achieve best results. Further, results have been compared on the basis of mean square error, number of neurons and accuracy. Hidden layer neurons have been varied from 2 to 8 , and obtained results have been compared in the context of complexity, computation time and accuracy. Total water samples dataset (50 samples) have been divided into three different datasets such as training, testing and validation. Training dataset consists of $70 \%$ of the dataset, while testing and validation consist of $15 \%$ each. Out of all three training techniques, conjugate gradient performs worst and predict results with highest mean square error (749-0.5439 for 2-8 neurons in hidden layer) and least accuracy $\left(R^{2}=86.38-99.98\right.$ for $2-8$ neurons in hidden layer), while Bayesian regulation performed best with least mean square error $\left(0.005 \times 10^{-5}\right)$ and with highest accuracy $\left(R^{2}=100 \%\right)$ at very less number of neurons in the hidden layer (4 neurons). Performance of all three training techniques has been compared based on the variation of mean square error with the variation of the number of neurons in the hidden layer (Table 1).

MLR and PCR also have shown the similar level of accuracy as ANN-based approach has shown. MLR and PCR are just linear models and take less computation time (less additions and multiplications) compared to neural network approach. MLR-based prediction model for water quality index prediction has used to train smartphone-based water quality monitoring system. Further, water quality index has been predicted for water samples collected from nearby villages of Rajasthan (Fig. 15). 


\section{Discussion and conclusion}

This paper reported a handy smartphone-based battery operated water quality measurement system to measure water quality for different applications. A smartphone-based application interface with various advanced features such as location-based data collection, storage on the cloud, integration with Google map for quick judgment, sensor calibration and many more has been introduced. System has been tested for various water quality measurement applications. Different statistical and ANN-based algorithms have been explored to predict water quality index. Presented work consists of various innovations such as location-based water quality measurement and storage, water quality indexing prediction, hassle-free operation, on-site calibration and many more. Presented work has been compared with past literature (Table 2), and it has been found that system could be a lowcost tool for water quality measurement at various rural and urban places. The overall system is cost-effective, portable and easy to use for villagers or any unskilled person.

Acknowledgements Authors wanted to thank Director CEERI for allowing us to develop such technology and also to publish this work. Authors also wanted to thank group members for providing their constant support in water samples collection and system testing.

Open Access This article is distributed under the terms of the Creative Commons Attribution 4.0 International License (http://creativeco mmons.org/licenses/by/4.0/), which permits unrestricted use, distribution, and reproduction in any medium, provided you give appropriate credit to the original author(s) and the source, provide a link to the Creative Commons license, and indicate if changes were made.

\section{References}

Applied Membranes Inc. home page, retrieved from https://www.appli edmembranes.com/chemical-test-kits-for-testing-water-quali ty.html

Bai V, Bouwmeester R, Mohan S (2009) Fuzzy logic water quality index and importance of water quality parameters. Air Soil Water Res 2:51-59

Bandyopadhyay $S$ et al (2016) A linearization scheme for thermistorbased sensing in biomedical studies. IEEE Sens J 16(3):603-609

Bartram J, Ballance R (eds) (1996) Water quality monitoring: a practical guide to the design and implementation of freshwater quality studies and monitoring programmes. CRC Press, Boca Raton

Central Pollution and Control Board (Ministry of Environment \& Forests) Guide manual: water and waste water analysis, Retrieved from http://cpcb.nic.in/upload/NewItems/NewItem_171_guide manualw\&wwanalysis.pdf

Cloete NA, Malekian R, Nair L (2016) Design of smart sensors for real-time water quality monitoring. IEEE Access 4:3975-3990

Daniel WL, Han MS, Lee JS, Mirkin CA (2009) Colorimetric nitrite and nitrate detection with gold nanoparticle probes and kinetic end points. J Am Chem Soc 131(18):6362-6363

De Marcellis A et al (2008) A CMOS integrable oscillator-based front end for high-dynamic-range resistive sensors. IEEE Trans Instrum Meas 57(8):1596-1604
Design, Single-Chip Solutions Simplify, and Accelerate Time-to-Market. Sensor AFE System

Dunbabin M, Grinham A, Udy J (2009) An autonomous surface vehicle for water quality monitoring. In: Australasian conference on robotics and automation (ACRA), pp 2-4

Ellerbee AK, Phillips ST, Siegel AC, Mirica KA, Martinez AW, Striehl P, Whitesides GM (2009) Quantifying colorimetric assays in paper-based microfluidic devices by measuring the transmission of light through paper. Anal Chem 81(20):8447-8452

Ethier A, Bedard J (2007) Development of a real-time water quality buoy for the fraser river estuary. In: OCEANS 2007, pp 1-6. IEEE

GH AAI (2015) Quality of tap drinking water in Kuwait: physicochemical characteristics. In: International conference on sustainable mobility applications, renewables and technology (SMART), 2015 (pp 1-4) IEEE

Gorashi F, Abdullah A (2012) Prediction of water quality index using back propagation network algorithm case study: Gombak river. J Eng Sci Technol 7(4):447-461

Grégoire G (2014) Multiple linear regression. Eur Astron Soc Publ Ser 66:45-72

Haider A, Roy AB, Sharma R, Hegde VN, Kumuda S (2016) AquaPredicto-Freshwater quality management system for lakes. In: Humanitarian technology conference (R10-HTC), 2016 IEEE Region 10, pp 1-8. IEEE

HANNA instruments, home page, retrieved from https://hannainst.com/ hi3817-water-quality-test-kit.html

Hossain A, Canning J, Ast S, Rutledge PJ, Yen TL, Jamalipour A (2015) Lab-in-a-phone: smartphone-based portable fluorometer for $\mathrm{pH}$ measurements of environmental water. IEEE Sens J 15(9):5095-5102

Ionel R et al (2015) Implementation of a GPRS based remote water quality analysis instrumentation. Measurement 65:81-93

Jolliffe IT (1982) A note on the use of principal components in regression. Appl Stat 31:300-303

Kafli N, Muhamad ZO, Khalid I (2016) Unsupervised floating platform for environmental monitoring. In: IEEE international conference on automatic control and intelligent systems (I2CACIS), IEEE

Khairi MTM, Ibrahim S, Yunus MAM, Faramarzi M (2015) Contact and non-contact ultrasonic measurement in the food industry: a review. Measur Sci Technol 27(1):012001

Komiyama R, Kageyama T, Miura M, Miyashita H, Lee SS (2015) Turbidity monitoring of lake water by transmittance measurement with a simple optical setup. In: SENSORS, 2015 IEEE, pp 1-4. IEEE

Konyha J (2016) Grid-based wide area water quality measurement system for surface water. In: Carpathian control conference (ICCC), 2016 17th International, pp 341-344. IEEE

Krishan G, Singh S, Kumar CP, Gurjar S, Ghosh NC (2016) Assessment of water quality index (WQI) of groundwater in Rajkot district, Gujarat, India. Earth Sci Clim Change 7(3):1-4

Lee BH, Deininger RA (1992) Optimal locations of monitoring stations in water distribution system. J Environ Eng 118(1):4-16

Marais JM, Bhatt DV, Hancke GP, Ramotsoela TD (2016) A webbased swimming pool information and management system. In: International conference on Industrial Informatics (INDIN), 2016 IEEE 14th, pp 980-985. IEEE

Murphy K, Heery B, Sullivan T, Zhang D, Paludetti L, Lau KT, Regan F (2015) A low-cost autonomous optical sensor for water quality monitoring. Talanta 132:520-527

Oscanoa H, La Chira H, Cuellar F (2016) Design and development of a Station for remote monitoring of non-domestic wastewater quality. In: ANDESCON, 2016 IEEE, pp 1-4. IEEE

Putra DA, Harsono T (2016) Smart sensor device for detection of water quality as anticipation of disaster environment pollution. In: 2016 International electronics symposium (IES), pp 87-92. IEEE 
Rasin Z, Abdullah MR (2009) Water quality monitoring system using zigbee based wireless sensor network. Int J Eng Technol 9(10):24-28

Regan F, Lawlor A, Flynn BO, Torres J, Martinez-Catala R, O'Mathuna C, Wallace J (2009) A demonstration of wireless sensing for long term monitoring of water quality. In: IEEE 34th Conference on local computer networks, 2009. LCN 2009. pp 819-825. IEEE

Roveda SRMM., Bondança APM, Silva JGS, Roveda JAF, Rosa AH (2010) Development of a water quality index using a fuzzy logic: a case study for the Sorocaba river. In: 2010 IEEE international conference on fuzzy systems (FUZZ), pp 1-5. IEEE

Sengupta M, Dalwani R (2007) Determination of water quality index and sustainability of an urban water body in Shimoga town, Karnataka. In: Proceedings of TAAL, pp 342-346

Sim SF, Ling TY, Lau S, Jaafar MZ (2015) A novel computeraided multivariate water quality index. Environ Monit Assess 187(4): 181

Singh SN, Srivastav G, Bhatt A (2012) Physicochemical determination of pollutants in wastewater in Dheradun. Curr World Environ 7(1):133-138

Siyang S, Kerdcharoen T (2016) Development of unmanned surface vehicle for smart water quality inspector. In: 2016 13th International conference on electrical engineering/electronics, computer, telecommunications and information technology (ECTI-CON), pp 1-5. IEEE
Sumriddetchkajorn S, Chaitavon K, Intaravanne Y (2013) Mobile device-based self-referencing colorimeter for monitoring chlorine concentration in water. Sens Actuators B Chem 182:592-597

Tyagi S, Sharma B, Singh P, Dobhal R (2013) Water quality assessment in terms of water quality index. Am J Water Resour 1(3):34-38

Vaddadi SK, Sadistap SS, Kumar P (2012) Development of embedded wireless network and water quality measurement systems for aquaculture. In: 2012 Sixth international conference on sensing technology (ICST), pp 637-641. IEEE

Wei Q, Nagi R, Sadeghi K, Feng S, Yan E, Ki SJ, Ozcan A (2014) Detection and spatial mapping of mercury contamination in water samples using a smart-phone. ACS Nano 8(2):1121-1129

Wiranto G, Maulana YY, Hermida IDP, Syamsu I, Mahmudin D (2015) Integrated online water quality monitoring. In: 2015 International conference on smart sensors and application (ICSSA), pp 111115. IEEE

Publisher's Note Springer Nature remains neutral with regard to jurisdictional claims in published maps and institutional affiliations. 